\title{
Net nitrogen uptake and DON release in surface waters: importance of trophic interactions implied from size fractionation experiments
}

\author{
B. B. Ward*, D. A. Bronk** \\ Institute of Marine Sciences, University of California, Santa Cruz, California 95064, USA
}

\begin{abstract}
Factors that influence the release of DON by planktonic assemblages were investigated using size fractionation experiments in the Southern California Bight and in Monterey Bay, California, USA. Incubation experiments, with either ${ }^{15} \mathrm{NH}_{4}{ }^{+}$or ${ }^{15} \mathrm{NO}_{3}{ }^{-}$as a tracer, were used to measure rates of net uptake (incorporation of DIN into particulate nitrogen [PN]) and DON release (production of DON during the incubation, through both active and passive mechanisms). DON release varied greatly among experiments and was higher when ${ }^{15} \mathrm{NO}_{3}{ }^{-}$was the substrate; it accounted for 3 to nearly $100 \%$ of the gross uptake (net uptake plus DON release). Compared with incubations with the $<10 \mu \mathrm{m}$ fraction alone, addition of the $<210 \mu \mathrm{m}$ fraction resulted in distinct patterns of change in net uptake and DON release. Whether the large fraction caused an increase or a decrease in net uptake or DON release rates probably depended on species composition as well as size distribution of trophic groups. DON release rates were positively correlated with $\mathrm{NH}_{4}{ }^{+}$regeneration rates $(\mathrm{p}<0.00001)$ and the magnitude of DON release was about $40 \%$ that of $\mathrm{NH}_{4}{ }^{+}$regeneration. The results imply that zooplankton and protozoan grazing - on primary producers, small heterotrophic plankton, and possibly bacteria - is a major mechanism of DON release. DON release was observed in every experiment and is clearly an important nitrogen flux in planktonic communities. If grazing is responsible for DON release, then standard incubation experiments probably underestimate the growth of phytoplankton by not accounting for grazing during incubations. The observed rates of DON release imply a rapid turnover of at least a portion of the total DON pool.
\end{abstract}

KEY WORDS: DON release $\cdot$ Net uptake $\cdot$ Size fractionation $\cdot$ Grazing

Resale or republication not permitted without written consent of the publisher

\section{INTRODUCTION}

Nitrogen availability is considered to be one of the main factors that limit phytoplankton production in the ocean, and therefore the patterns and magnitude of nitrogen assimilation rates by phytoplankton assemblages have been widely studied. The framework within which much of this work has been done is referred to as the new production paradigm (Dugdale \& Goering 1967, Eppley \& Peterson 1979). The role of

Present addresses:

${ }^{*}$ Department of Geosciences, Princeton University, Princeton, New Jersey 08544, USA. E-mail: bbw@princeton.edu

** Department of Physical Sciences, Virginia Institute of Marine Sciences, College of William and Mary, Gloucester Point, Virginia 23062, USA grazing in this paradigm is to link primary production to the regenerated nitrogen that sustains production. Ammonium regeneration has been measured in primary production experiments and is often found to occur at a rate comparable with that of $\mathrm{NH}_{4}{ }^{+}$assimilation (Glibert et al. 1991, Dickson \& Wheeler 1995). Although fewer data are available, production of DON is also now recognized as an important nitrogen flux, which may be linked to primary production and grazing (Bronk \& Glibert 1993a, Pujo-Pay et al. 1997, Hu \& Smith 1998, Bronk \& Ward 1999, Raimbault et al. 1999). The mechanisms of DON release and the magnitude of the release compared with nitrogen assimilation and $\mathrm{NH}_{4}{ }^{+}$regeneration are not well understood. If DON release is of the same magnitude as net uptake (production of particulate nitrogen [PN]) and $\mathrm{NH}_{4}{ }^{+}$regeneration, then it is a 
significant flux of DIN that is not adequately represented in current models and conceptualizations of the nitrogen cycle in surface waters. Significant DON release rates would also imply a more active DON pool, and these rates would verify the presence or increased importance of previously unappreciated mechanisms and pathways for DON production and consumption.

The stable isotope ${ }^{15} \mathrm{~N}$ has been used extensively to measure new and regenerated production. One common phenomenon in ${ }^{15} \mathrm{~N}$ tracer studies is referred to as the missing ${ }^{15} \mathrm{~N}$ (Glibert et al. 1982, Ward et al. 1989, Bronk \& Glibert 1994). Even when ${ }^{15} \mathrm{~N}$ in all the major soluble inorganic pools and in PN was measured, a variable and sometimes large proportion of the total label added at the beginning of the experiment could not be accounted for at the end. Ward et al. (1989) suggested on the basis of this discrepancy that some of the label might be found in DON. In studies conducted in estuarine and coastal waters, Bronk \& Glibert showed that DON was both released (1991, 1993a) and assimilated by the planktonic community (1993a). In a size fractionation study conducted in a subestuary of Chesapeake Bay, Bronk \& Glibert (1993a) measured total and low molecular weight DON release in the $<1.2$ and $<210 \mu \mathrm{m}$ size fractions over a 24 to $36 \mathrm{~h}$ period. In the $<1.2 \mu \mathrm{m}$ fraction, DON release was virtually all low molecular weight in composition and was attributed to direct release by the microorganisms. Release of low molecular weight DON was similar in both the $<1.2$ and $<210 \mu \mathrm{m}$ fractions. Total DON release (including high molecular weight components) was much higher in the $<210 \mu \mathrm{m}$ fraction, and this release was attributed to grazing.

The experiments described here were designed to investigate the production of DON during conventional ${ }^{15} \mathrm{~N}$ tracer experiments in oceanic and coastal waters and to investigate the impact of the inclusion of large grazers (i.e., the $>10 \mu \mathrm{m}$ fraction) on the amount of ${ }^{15} \mathrm{~N}$ transferred to the DON pool. Size fractionation experiments were used to identify the trophic interactions that might be important in causing DON production. A protocol in which most of the DIN, DON, and PN fractions were analyzed for nitrogen concentration and ${ }^{15} \mathrm{~N}$ content was used in order to obtain mass balance. These results show that DON is an important fate of DIN, in addition to PN, and its release during grazing can partially account for the discrepancy between nitrogen assimilation and particulate production.

\section{MATERIALS AND METHODS}

Experimental sites. Experiments were performed in the Southern California Bight (SCB) at stations in Santa Monica and San Pedro basins (see exact locations in results of each experiment, below) in October
1992 and April 1994, and in Monterey Bay, California (MB), USA in March and September 1993; all MB experiments were performed at the central station $\mathrm{H} 3$, $36^{\circ} 46.7 \mathrm{~N}, 122^{\circ} 01.0 \mathrm{~W}$, in approximately $900 \mathrm{~m}$ of water over the submarine canyon.

Size fractionation experiments. Water was collected in $30 \mathrm{l}$ Go-Flow bottles (General Oceanics, Miami, FL) and filtered by gravity through either 10 or $210 \mu \mathrm{m}$ mesh Nitex (Sefar Filtration, Lancaster, NY) directly into acid cleaned 41 polycarbonate bottles, being careful to keep the Nitex submerged during filtration. ${ }^{15} \mathrm{~N}$ tracer (either $\mathrm{NH}_{4}{ }^{+}$or $\mathrm{NO}_{3}{ }^{-}$at approximately $10 \%$ of ambient concentration or $100 \mathrm{nM}$ final concentration, if the ambient concentration was below $1 \mu \mathrm{M}$ ) was added and the bottles were incubated for $3 \mathrm{~h}$ in simulated in situ light conditions in flowing seawater incubators on deck. In October 1992, deck incubators were constructed of clear plexiglass and layers of neutral-density nickel-plated screens accomplished light attenuation. For the other 3 cruises, deck incubators were constructed of clear plexiglass and light attenuation was obtained by adding variable numbers of blue plexiglass shields to the sides and top of the incubator. Three hour incubations were chosen on the basis of previous oceanic experiments that showed rapid depletion of substrate over short time scales (Ward et al. 1989); $3 \mathrm{~h}$ was also the shortest practical incubation period. Incubations were initiated at either $09: 00 \mathrm{~h}$ or $21: 00 \mathrm{~h}$ to measure day or night rates, respectively. After $3 \mathrm{~h}$, the contents of each bottle were filtered onto combusted $47 \mathrm{~mm}$ diameter $\mathrm{GF} / \mathrm{F}$ filters using gentle vacuum $(<6.6 \mathrm{kPa})$, and care was taken to ensure that the filters were not allowed to dry or to be exposed to bright light. The filter and aliquots of the filtrates were frozen immediately and returned to the laboratory for analysis.

Nitrogen isotopic analyses. The filters were dried and portions of them were used for determination of total carbon and nitrogen by CHN analysis (Control Equipment CHN Analyzer, Exeter Analytical, North Chelmsford, MA). Replicate filters or portions of them were then used for determination of the atom\% enrichment using emission spectrometry (JASCO model N-150, Jasco Ltd, Tokyo; Fiedler \& Proksch 1975) or mass spectrometry (Europa 20/20 isotope ratio mass spectrometer PDZ Europa, Cheshire, UK). The filtrates were divided into aliquots and used for the determination of nitrogen concentrations and atom\% enrichment of the various soluble pools. The details of these methods are described by Bronk \& Ward (1999) and are only briefly described here. Ammonia was collected by distillation (Glibert et al. 1982) of a $200 \mathrm{ml}$ aliquot; the distillate was evaporated to reduce its volume, spotted onto combusted glass fiber filters and subsequently analyzed for isotopic ratio by emission spectrometry. To isolate $\mathrm{DON}, \mathrm{NO}_{3}{ }^{-}$was removed from the same 
sample by reduction to $\mathrm{NH}_{4}{ }^{+}$using Devarda's alloy during boiling to remove both $\mathrm{NO}_{3}{ }^{-}$and $\mathrm{NH}_{4}{ }^{+}$ (described in detail in Bronk \& Ward 1999). The remaining aliquot was UV oxidized (Armstrong \& Tibbits 1968) using $\mathrm{H}_{2} \mathrm{O}_{2}$ as a catalyst, resulting in the stoichiometric conversion of DON to nitrate. The resulting $\mathrm{NO}_{3}{ }^{-}$was reduced to $\mathrm{NO}_{2}{ }^{-}$using spongy cadmium (Jones 1984) and the resulting $\mathrm{NO}_{2}^{-}$was extracted using the organic extraction method previously described (Olson 1981, Ward et al. 1984). At sea, filtrate aliquots (up to 2 l) were extracted directly for $\mathrm{NO}_{2}{ }^{-}$. The organic nitrogen dye containing the nitrogen from $\mathrm{NO}_{2}{ }^{-}, \mathrm{NO}_{2}{ }^{-}$plus $\mathrm{NO}_{3}{ }^{-}$, or DON, was spotted onto combusted glass fiber filters and used for isotopic determination by emission spectrometry. Isotopic ratio measurements were made for $\mathrm{NH}_{4}{ }^{+}, \mathrm{NO}_{3}{ }^{-}, \mathrm{PN}$, and DON fractions in all experiments at the end of the incubation. DON atom\% enrichments were corrected for possible residual $\mathrm{NH}_{4}{ }^{+}$or $\mathrm{NO}_{3}{ }^{-}$present in the final isolated DON fraction. The efficiency of removal of $\mathrm{NH}_{4}{ }^{+}$and $\mathrm{NO}_{3}{ }^{-}$was determined empirically to be $100 \%$. This determination depended, however, on wet chemical analyses of $\mathrm{NH}_{4}{ }^{+}$and $\mathrm{NO}_{3}{ }^{-}$, which have limits of detection of $\sim 0.03$ to $0.05 \mu \mathrm{M}$. Accordingly, we applied a correction similar to that used by Bronk \& Glibert (1991) to correct for possible residual $\mathrm{NH}_{4}{ }^{+}$or $\mathrm{NO}_{3}{ }^{-}$. The ${ }^{15} \mathrm{~N}$ atom\% enrichment of the residual $\mathrm{NH}_{4}{ }^{+}$or $\mathrm{NO}_{3}{ }^{-}$was taken to be the same as that measured at the end of the incubation.

DIN, DON, and chlorophyll a concentration measurements. Ammonia was measured manually by the method of Grasshoff et al. (1983), and $\mathrm{NO}_{3}{ }^{-}$(Technicon autoanalyzer II, Pulse Instrumentation Ltd, Saskatoon, SK, Canada) and $\mathrm{NO}_{2}^{-}$(manually) by the methods of Strickland \& Parsons (1972). DON concentrations were obtained by $\mathrm{NO}_{3}{ }^{-}$analysis of UV-oxidized seawater (Armstrong \& Tibbits 1968) using a $1200 \mathrm{~W}$ mercury vapor lamp and irradiation for $18 \mathrm{~h}$. Though the UV method can be unreliable, likely because of variations in UV lamps, the lamp used in this study yielded recoveries of standard $\mathrm{NH}_{4}{ }^{+}$and cAMP standards of $\geq 94 \%$ (Bronk et al. 2000). Samples for determination of ambient nutrient concentrations were collected from the sampling bottle at the time of sample collection and samples were then collected from each of the incubation bottles at the end of the incubation. Chlorophyll $a$ (chl a), corrected for phaeopigments, was measured using the fluorometric techniques of Parsons et al. (1984) on filtered samples collected after the tracer incubations.

Rate calculations. Nitrogen transformation rates were calculated using equations modeled after those of Glibert et al. (1982), i.e., taking into account the decrease in isotopic enrichment in the substrate pool over time. Rates of net uptake (uptake of the labeled sub- strate into PN) and DON release were calculated as described by Bronk et al. (1994, 1998). Gross uptake refers to the sum of net uptake and DON release. Net uptake is the term usually equated with uptake and assimilation in conventional ${ }^{15} \mathrm{~N}$ experiments in which DON release is not measured.

The difference in rates of net uptake, DON release and ammonia regeneration between the 2 fractions represents the portion of each process that was attributable to the presence of organisms between 10 and $210 \mu \mathrm{m}$ in size or to some interaction between the size fractions. Lower DON release rates in the $<210 \mu \mathrm{m}$ incubation than in the $<10 \mu \mathrm{m}$ incubation imply either consumption of DON or prevention of its release because of some interaction between organisms in the different size classes. Conversely, higher DON release in the $<210 \mu \mathrm{m}$ than in the $<10 \mu \mathrm{m}$ incubations implicates larger organisms in the release of DON.

Treatments within individual experiments were not replicated because of the labor-intensive nature of the measurements. Instead, the same kinds of experiments were repeated several times on 4 cruises (see above). A total of 38 incubations resulted from 4 cruises, measuring 2 substrates at 2 to 3 depths, both day and night, at both coastal and oceanic sites. Experiments have not been grouped for statistical analysis because the repeated experiments do not constitute true replicates. Where possible, isotopic analyses were repeated on up to 3 subsamples of each incubation. Where error bars appear on the plots, they represent the standard deviation associated with replicate assay results from the same experiment. Errors associated with the calculated rates were propagated as described in Bevington (1969); the error associated with a calculated rate includes errors accumulated in replicate measurements of $\mathrm{N}$ concentration (substrate and product) and isotopic content (substrate and product). Where no error bars are evident, the standard deviation was zero (this happened only with the PN measurements) or too small to visualize on the plot. Missing bars represent lost samples. Rates were taken to be different from each other if their standard deviations did not overlap.

\section{RESULTS}

Net uptake and DON release rates in the $<10$ and $<210 \mu \mathrm{m}$ fractions are shown for all experiments in Figs 1 to 4. Results for daytime experiments in MB during March 1993 and in the SCB in October 1992 are found in Figs $1 \& 2$. Next, the results of night versus day experiments for 2 stations in the SCB in April 1994 and in MB in September 1993 are presented (Figs 3 \& 4). Nutrient concentrations for each incubation experiment are reported in Table 1. Chlorophyll and PN con- 

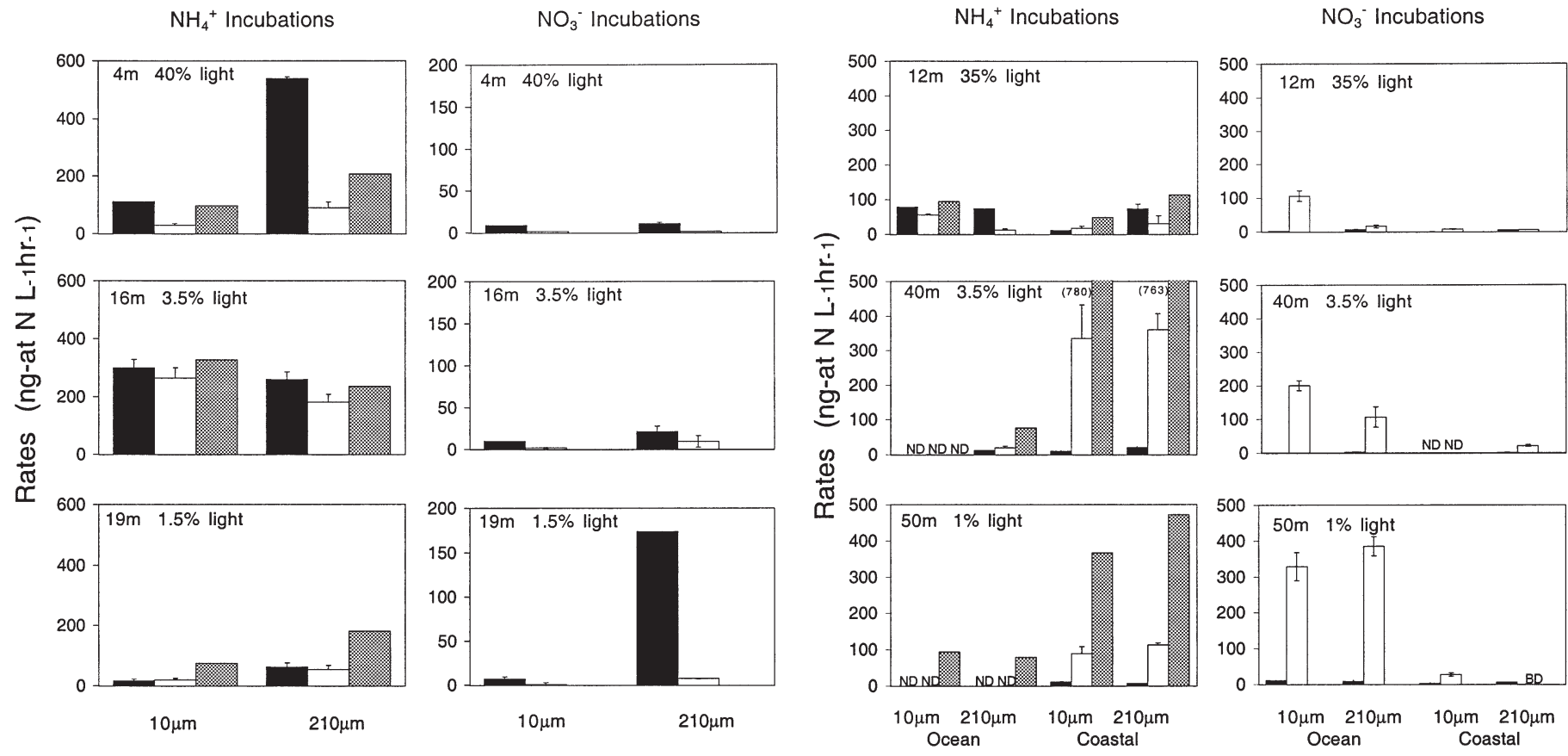

Fig. 1. $\mathrm{NH}_{4}{ }^{+}$and $\mathrm{NO}_{3}{ }^{-}$uptake (घ), DON release ( $\square$ ), and $\mathrm{NH}_{4}{ }^{+}$ regeneration (讁) rates $\left(\mathrm{ng} \mathrm{l}^{-1} \mathrm{~h}^{-1}\right)$ in size fraction experiments from March 1993, Monterey Bay. $\mathrm{NH}_{4}{ }^{+}$regeneration was not measured in the $\mathrm{NO}_{3}{ }^{-}$incubations. $\mathrm{BD}$ : below detection; $\mathrm{ND}$ :

Fig. 2. Size fraction experiments from October 1992, Southern California Bight. See Fig. 1 for abbreviations and symbol definitions

Table 1. Nutrient concentrations measured in size fractionation experiments. Except for the September experiments, for which some nutrient samples were lost, measurements were made before incubations on water collected from the same cast and the same Niskin samplers that were used in the experiment. In September, nutrient data from the closest cast (12 h lag) are presented. For the October coastal experiments, nutrient samples were collected before fractionation; for March and April, nutrient samples were collected from the size fractionated samples before incubation

\begin{tabular}{|lccccccccc|}
\hline Experiment & Depth $(\mathrm{m})$ & $\mathrm{NO}_{3}$ & $(\mathrm{SD})$ & $\mathrm{NO}_{2}$ & $(\mathrm{SD})$ & $\mathrm{NH}_{4}$ & $(\mathrm{SD})$ & $\mathrm{DON}$ & $(\mathrm{SD})$ \\
\hline March day & 4 & 0.22 & $(0.01)$ & 0.01 & $(0.009)$ & 0.43 & $(0.05)$ & 5.36 & $(0.08)$ \\
& 16 & 1.42 & $(0.11)$ & 0.23 & $(0.004)$ & 0.24 & $(0.05)$ & 5.8 & $(0.13)$ \\
October coastal & 19 & 0.89 & $(0.09)$ & 0.23 & $(0.055)$ & 0.03 & $(0.01)$ & 4.47 & $(0.05)$ \\
& 11.5 & 0.17 & $(0.00)$ & 0.03 & $(0.000)$ & 0.17 & $(0.00)$ & 6.74 & $(0.07)$ \\
October oceanic & 35.5 & 0.73 & $(0.02)$ & 0.14 & $(0.021)$ & 2.33 & $(0.13)$ & 9.41 & $(0.19)$ \\
& 49 & 2.58 & $(0.10)$ & 0.39 & $(0.094)$ & 1.02 & $(0.16)$ & 7.00 & $(0.17)$ \\
April day & 12.5 & 0.06 & $(0.01)$ & 0.03 & $(0.005)$ & 0.15 & $(0.00)$ & 6.52 & $(0.01)$ \\
April night & 40 & 1.23 & $(0.23)$ & 0.11 & $(0.011)$ & 0.29 & $(0.00)$ & 6.58 & $(0.25)$ \\
& 55 & 4.39 & $(0.09)$ & 0.89 & $(0.092)$ & 0.25 & $(0.11)$ & 6.97 & $(0.12)$ \\
September day & 3.5 & 0.12 & $(0.00)$ & 0.01 & $(0.00)$ & 0.01 & $(0.02)$ & 5.31 & $(0.31)$ \\
& 43 & 11.7 & $(0.35)$ & 0.36 & $(0.043)$ & 0.16 & $(0.03)$ & 6.11 & $(1.24)$ \\
September night & 3.5 & 0.01 & $(0.15)$ & 0.01 & $(0.002)$ & 0.01 & $(0.01)$ & 5.11 & $(0.51)$ \\
& 43 & 12.64 & $(0.34)$ & 0.26 & $(0.004)$ & 0.03 & $(0.01)$ & 3.27 & $(1.10)$ \\
& 0 & 0.47 & $(0.02)$ & 0.16 & $(0.008)$ & 0.00 & $(0.00)$ & 5.18 & $(0.42)$ \\
& 20 & 1.3 & $(0.01)$ & 0.11 & $(0.015)$ & 0.01 & $(0.01)$ & 7.62 & $(0.20)$ \\
& 30 & 1.2 & $(0.03)$ & 0.21 & $(0.009)$ & 0.71 & $(0.02)$ & 7.67 & $(0.24)$ \\
& 30 & 0.52 & $(0.02)$ & 0.002 & $(0.002)$ & 0.00 & $(0.00)$ & 4.25 & $(0.17)$ \\
& & 1.3 & $(0.02)$ & 0.04 & $(0.018)$ & 0.06 & $(0.01)$ & 5.77 & $(0.24)$ \\
& 0.92 & $(0.01)$ & 0.21 & $(0.004)$ & 0.46 & $(0.01)$ & 6.15 & $(0.24)$ \\
& & & & & & & & & \\
\end{tabular}



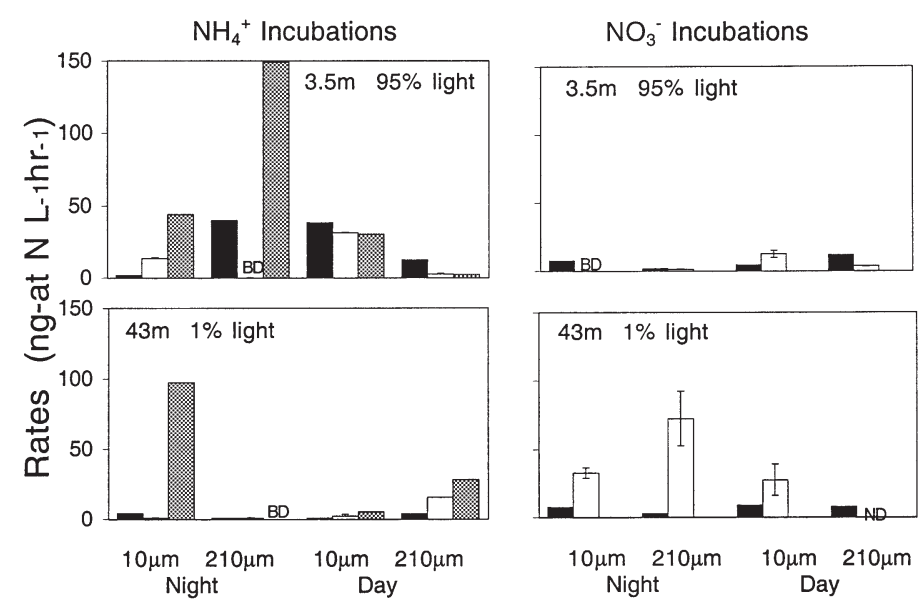

Fig. 3. Size fraction experiments from April 1994, Southern California Bight. See Fig. 1 for abbreviations and symbol definitions

centrations, and useful ratios for consideration of community composition are reported in Table 2 .

\section{Daytime experiments}

\section{March 1993}

The 3 depths in this experiment spanned the photic zone from $40(4 \mathrm{~m})$ to $1.5 \%$ light $(19 \mathrm{~m})$. Nitrate concentrations were less than $1 \mu \mathrm{M}$ at $4 \mathrm{~m}$ and increased to 1.5 to $2 \mu \mathrm{M}$ at $19 \mathrm{~m}$, while $\mathrm{NH}_{4}{ }^{+}$was present at less than $0.5 \mu \mathrm{M}$ at all depths (Table 1). Most of the PN was in the small size fraction (Table 2). Essentially all of the chl a was $<10 \mu \mathrm{m}$ at $4 \mathrm{~m}$, but less than half of the chl $a$ was in the small fraction at 16 and $19 \mathrm{~m}$.

At 4 and $16 \mathrm{~m}, \mathrm{NH}_{4}{ }^{+}$assimilation rates greatly exceeded $\mathrm{NO}_{3}{ }^{-}$assimilation rates in both size fractions (Fig. 1). Only at $19 \mathrm{~m}$ did the rate of $\mathrm{NO}_{3}{ }^{-}$uptake approach or exceed the rate of $\mathrm{NH}_{4}{ }^{+}$uptake (Fig. 1). In the ${ }^{15} \mathrm{NH}_{4}$ incubations, net uptake predominated over DON release at $4 \mathrm{~m}$, while at 16 and $19 \mathrm{~m}$, the rates of net uptake and DON release were about the same. In the ${ }^{15} \mathrm{NO}_{3}$ incubations, net uptake exceeded DON release in the larger size fraction. $\mathrm{NH}_{4}{ }^{+}$regeneration exceeded the release of DON at all depths.

\section{October 1992}

In October 1992, 2 size fraction experiments were conducted in SCB, both during daylight. Both sampled the water column at the same relative light intensities, but one experiment was offshore (referred to as oceanic, station $305,33.45^{\circ} \mathrm{N}, 118.47^{\circ} \mathrm{W}$ ) and one inshore (referred to as coastal, station $303,33.53^{\circ} \mathrm{N}$, $\left.118.31^{\circ} \mathrm{W}\right)$, so that deeper depths were sampled at the oceanic, versus coastal, station. Incubations were performed at $35,3.5$ and $1 \%$ light $(11.5,35.5$, and $49 \mathrm{~m}$ at the coastal station and $12.5,40$, and $55 \mathrm{~m}$ at the oceanic station, respectively). At the oceanic station, $\mathrm{NH}_{4}{ }^{+}$was present at all depths at around 0.1 to $0.3 \mu \mathrm{M}$, while $\mathrm{NO}_{3}{ }^{-}$was near the limit of detection at the surface and increased with depth (Table 1). At the coastal station, $\mathrm{NH}_{4}^{+}$and $\mathrm{NO}_{3}^{-}$concentrations were low in surface waters and both increased with depth (Table 1). Most of the PN was small and, for all but 2 of the October experiments, most of the chl a was in the smaller size fraction.

DON release from $\mathrm{NH}_{4}{ }^{+}$generally exceeded net uptake (Fig. 2) except at $3.5 \%$ light. In all experiments in which DON release data were obtained from both size fractions, it was not possible to detect any contribution to DON release by the larger fraction (over that produced by the small fraction alone). Ammonium regeneration rates generally exceeded both net uptake and DON release rates (Fig. 2).

Net uptake rates from $\mathrm{NO}_{3}{ }^{-}$were uniformly low and usually greatly exceeded by DON release. At the shallowest depth in the oceanic experiment, most of the DON release was associated with the small fraction, and DON release was greatly reduced in the presence of the larger fraction. DON release rates from ${ }^{15} \mathrm{NO}_{3}{ }^{-}$ increased with depth, and at $1 \%$ light, DON release was apparently not affected by the presence of the larger size fraction. Rates of DON release from $\mathrm{NO}_{3}^{-}$
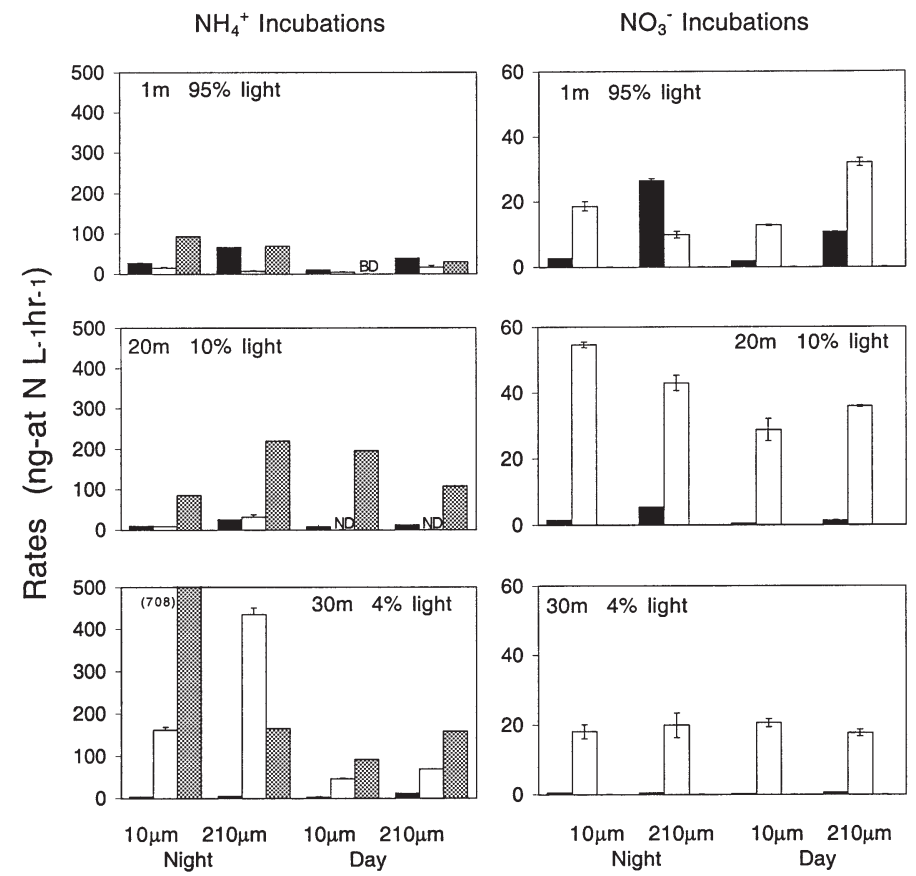

Fig. 4. Size fraction experiments from September 1993, Monterey Bay. See Fig. 1 for abbreviations and symbol definitions 
were highest at $1 \%$ light for both the coastal and the oceanic experiments.

\section{Night versus day experiments}

\section{April 1994}

Two size fraction experiments, one during the day and one at night, were conducted at 2 depths (3.5 and $43 \mathrm{~m}$ ) corresponding to 95 and $1 \%$ light at an offshore station (Stn 205; $33.17^{\circ} \mathrm{N}, 118.09^{\circ} \mathrm{W}$ ) in the SCB. The 2 experiments were performed within $48 \mathrm{~h}$ of each other at the same station; nutrient, chl $a$, and PN distributions were not discernibly different between the 2 experiments. Ammonium concentrations were low, less than $0.2 \mu \mathrm{M}$ and often undetectable, at both depths for both day and night experiments (Table 1). Nitrate was $<0.5 \mu \mathrm{M}$ at $3.5 \mathrm{~m}$ and increased to $\sim 12 \mu \mathrm{M}$ at $43 \mathrm{~m}$; the experiment at the $43 \mathrm{~m}$ depth was the only 1 reported here in which relatively high $\mathrm{NO}_{3}^{-}$levels were present. Upwards of $80 \%$ of the PN, and on average $94 \%$ of the chl $a$, was present in the small size fraction at all depths in both day and night experiments (Table 2).

At $3.5 \mathrm{~m}$, net uptake rates from $\mathrm{NH}_{4}{ }^{+}$were lower in the small size fraction at night than in the day, but the opposite was true for the whole sample $(<210 \mu \mathrm{m})$ (Fig. 3). In contrast, net uptake was greater in the small fraction at night and in the large fraction during the day, while DON release varied in the opposite manner. $\mathrm{NH}_{4}{ }^{+}$regeneration rates were greater in the $<210 \mu \mathrm{m}$ fraction at night and in the $<10 \mu \mathrm{m}$ fraction during the day.

DON release rates usually exceeded net uptake from $\mathrm{NO}_{3}{ }^{-}$for both day and night (in 4 of the 6 experiments in which both rates were measured). These DON release rates exceeded net uptake and DON release rates in all other April experiments and were on the same order as the highest $\mathrm{NH}_{4}{ }^{+}$regeneration rates. Ammonium regeneration rates exceeded both net uptake and DON release from $\mathrm{NH}_{4}{ }^{+}$at night for both depths and in the day at $43 \mathrm{~m}$.

\section{September 1993}

One experiment during the day and one at night, both including 3 depths, were con-
Table 2. Particulate nitrogen (PN) and cholorophyll a (Chl a) data for each size fraction in each experiment

\begin{tabular}{|c|c|c|c|c|c|}
\hline & $\begin{array}{l}\text { Depth } \\
(\mathrm{m})\end{array}$ & $\begin{array}{l}\text { Size fraction } \\
(\mu \mathrm{m})\end{array}$ & $\begin{array}{l}\text { Chl } a \\
(\mu g)\end{array}$ & $\begin{array}{c}\text { PN } \\
(\mu \mathrm{M})\end{array}$ & Chl $a: P N$ \\
\hline March day & 4 & 10 & 0.28 & 1.36 & 0.21 \\
\hline \multirow[t]{5}{*}{$\mathrm{NH}_{4}$} & 4 & 210 & & 1.96 & nd \\
\hline & 16 & 10 & 0.50 & 1.48 & 0.34 \\
\hline & 16 & 210 & 1.24 & 1.99 & 0.62 \\
\hline & 19 & 10 & 0.60 & 1.34 & 0.45 \\
\hline & 19 & 210 & 1.03 & 1.78 & 0.58 \\
\hline March day & 4 & 10 & 0.60 & 1.49 & 0.40 \\
\hline \multirow[t]{5}{*}{$\mathrm{NO}_{3}$} & 4 & 210 & 0.51 & 2.16 & 0.24 \\
\hline & 16 & 10 & 0.27 & 1.42 & 0.19 \\
\hline & 16 & 210 & 0.77 & 1.87 & 0.41 \\
\hline & 19 & 10 & & 1.40 & nd \\
\hline & 19 & 210 & 1.10 & 1.81 & 0.61 \\
\hline October coastal & 11.5 & 10 & 0.16 & 0.50 & 0.33 \\
\hline \multirow[t]{5}{*}{$\mathrm{NH}_{4}$} & 11.5 & 210 & 0.19 & 0.69 & 0.28 \\
\hline & 35.5 & 10 & 0.31 & 0.64 & 0.49 \\
\hline & 35.5 & 210 & 0.40 & 0.99 & 0.40 \\
\hline & 49 & 10 & 0.27 & 0.86 & 0.31 \\
\hline & 49 & 210 & 0.21 & 0.61 & 0.35 \\
\hline October coastal & 11.5 & 10 & 0.19 & 0.67 & 0.29 \\
\hline \multirow[t]{5}{*}{$\mathrm{NO}_{3}$} & 11.5 & 210 & 0.22 & 0.71 & 0.31 \\
\hline & 35.5 & 10 & 0.38 & 0.89 & 0.42 \\
\hline & 35.5 & 210 & 0.51 & 0.90 & 0.56 \\
\hline & 49 & 10 & 0.24 & 0.70 & 0.34 \\
\hline & 49 & 210 & 0.32 & 1.19 & 0.27 \\
\hline October oceanic & 12.5 & 10 & 0.27 & 0.92 & 0.29 \\
\hline \multirow[t]{5}{*}{$\mathrm{NH}_{4}$} & 12.5 & 210 & 0.45 & 1.10 & 0.42 \\
\hline & 40 & 10 & 0.30 & 0.60 & 0.51 \\
\hline & 40 & 210 & 0.79 & 0.95 & 0.84 \\
\hline & 55 & 10 & 0.19 & 0.29 & 0.67 \\
\hline & 55 & 210 & 0.95 & 0.47 & 2.01 \\
\hline October oceanic & 12.5 & 10 & 0.32 & 0.87 & 0.37 \\
\hline \multirow{5}{*}{$\mathrm{NO}_{3}$} & 12.5 & 210 & 0.63 & 1.21 & 0.52 \\
\hline & 40 & 10 & 0.41 & 0.61 & 0.67 \\
\hline & 40 & 210 & 0.51 & 1.25 & 0.41 \\
\hline & 55 & 10 & 0.33 & 2.97 & 0.44 \\
\hline & 55 & 210 & 0.42 & 0.76 & 0.14 \\
\hline April day & 3.5 & 10 & & 0.86 & \\
\hline \multirow[t]{3}{*}{$\mathrm{NH}_{4}$} & 3.5 & 202 & & 1.00 & \\
\hline & 43 & 10 & & 0.34 & \\
\hline & 43 & 202 & & 0.25 & \\
\hline April day & 3.5 & 10 & & 0.80 & \\
\hline \multirow[t]{3}{*}{$\mathrm{NO}_{3}$} & 3.5 & 202 & & 1.00 & \\
\hline & 43 & 10 & & 0.30 & \\
\hline & 43 & 202 & & 0.26 & \\
\hline April night & 3.5 & 10 & & 0.76 & \\
\hline \multirow[t]{3}{*}{$\mathrm{NH}_{4}$} & 3.5 & 202 & & 0.88 & \\
\hline & 43 & 10 & & 0.41 & \\
\hline & 43 & 202 & & 0.49 & \\
\hline April night & 3.5 & 10 & & 0.67 & \\
\hline \multirow[t]{3}{*}{$\mathrm{NO}_{3}$} & 3.5 & 202 & & 0.87 & \\
\hline & 43 & 10 & & 0.41 & \\
\hline & 43 & 202 & & 0.47 & \\
\hline September day & 0 & 10 & 0.58 & 0.89 & 0.65 \\
\hline \multirow[t]{5}{*}{$\mathrm{NH}_{4}$} & 0 & 202 & 0.88 & 1.49 & 0.59 \\
\hline & 20 & 10 & 0.58 & 0.56 & 1.03 \\
\hline & 20 & 202 & 0.88 & 0.85 & 1.04 \\
\hline & 30 & 10 & 0.43 & 0.36 & 1.18 \\
\hline & 30 & 202 & 0.61 & 0.71 & 0.86 \\
\hline
\end{tabular}


Table 2 (continued)

\begin{tabular}{|lrrrrr|}
\hline & $\begin{array}{c}\text { Depth } \\
(\mathrm{m})\end{array}$ & $\begin{array}{c}\text { Size fraction } \\
(\mu \mathrm{m})\end{array}$ & $\begin{array}{c}\text { Chl a } \\
(\mu \mathrm{g})\end{array}$ & $\begin{array}{c}\text { PN } \\
(\mu \mathrm{M})\end{array}$ & Chl a:PN \\
\hline September day & 0 & 10 & 0.58 & 1.09 & 0.54 \\
$\mathrm{NO}_{3}$ & 0 & 202 & 0.84 & 1.34 & 0.63 \\
& 20 & 10 & 0.41 & 0.7 & 0.59 \\
& 20 & 202 & 0.86 & 1.12 & 0.76 \\
& 30 & 10 & 0.41 & 0.55 & 0.75 \\
& 30 & 202 & 0.61 & 0.64 & 0.95 \\
September night & 0 & 10 & 0.7 & 1.08 & $0 ., 65$ \\
$\mathrm{NH}_{4}$ & 0 & 202 & 2.35 & 2.86 & 0.82 \\
& 20 & 10 & 0.95 & 1.4 & 0.68 \\
& 20 & 202 & 4.07 & 2.95 & 1.38 \\
& 30 & 10 & 0.61 & 0.76 & 0.81 \\
September night & 30 & 202 & 1.2 & 1.19 & 1.01 \\
$\mathrm{NO}_{3}$ & 0 & 10 & 0,75 & 1,15 & 0,65 \\
& 0 & 202 & 2,08 & 2,82 & 0,74 \\
& 20 & 10 & 0,88 & 1,42 & 0,62 \\
& 20 & 202 & 3,73 & 2,94 & 1,27 \\
& 30 & 10 & 0,6 & 0,68 & 0,89 \\
& 30 & 202 & 1,33 & 1,05 & 1,27 \\
\hline
\end{tabular}

up to $99 \%$ of gross uptake of $\mathrm{NH}_{4}{ }^{+}$. Most of the net uptake and DON release were associated with the larger size fraction (Fig. 4). Ammonium regeneration rates ranged from comparable to much greater than net uptake from $\mathrm{NH}_{4}{ }^{+}$and usually exceeded DON release from $\mathrm{NH}_{4}^{+}$(8 of 9 cases where both rates were detected). In 2 of 3 night experiments and both day experiments where the comparison is possible, $\mathrm{NH}_{4}{ }^{+}$regeneration and DON release exhibited the same pattern of relative magnitude between size fractions. That is, both rates were higher in the large fraction than in the small fraction at $20 \mathrm{~m}$ at night, and both were smaller in the large fraction at $1 \mathrm{~m}$ at night. These patterns may aid in deducing the mechanisms of DON production (see below).

The rates of net $\mathrm{NO}_{3}{ }^{-}$uptake were lower than uptake rates for $\mathrm{NH}_{4}{ }^{+}$. DON release predominated over net $\mathrm{NO}_{3}{ }^{-}$uptake at all depths

ducted in MB in September 1993. Nitrate was present at $\sim 0.5 \mu \mathrm{M}$ at $1 \mathrm{~m}$, increasing to $1.25 \mu \mathrm{M}$ at the 2 deeper depths. Ammonium concentrations also increased with depth, from about $0.1 \mu \mathrm{M}$ at $1 \mathrm{~m}$ to $0.7 \mu \mathrm{M}$ at $30 \mathrm{~m}$ (Table 1). During the day, greater than half of the PN and chl a was present in the smaller size fraction at all depths (Table 2). At night, the fraction of chl $a$ in the smaller size fraction dropped at all depths, except at $30 \mathrm{~m}$, where it increased slightly. These changes were caused mainly by a large increase in the chl a concentration of the larger size fraction; the chl $a$ and $\mathrm{PN}$ concentrations of the smaller size fraction also increased between the day and night experiments, but to a lesser degree. These 2 experiments were performed within the same $24 \mathrm{~h}$ period at the same station. Such a dramatic shift in the population composition and size may have been caused by advection of a bloom of larger phytoplankton. It seems unlikely that growth of the in situ population could produce a tripling or quadrupling of the chl a content over a period of $12 \mathrm{~h}$. Ambient nutrient concentrations were not very different between day and night experiments (Table 1) and do not help to explain the apparent shift between the 2 experiments.

In ${ }^{15} \mathrm{NH}_{4}{ }^{+}$incubations, rates of net uptake and DON release showed the same clear trend with depth in both day and night experiments (Fig. 4). Rates were higher overall at night, consistent with the higher phytoplankton biomass (implied from chl a concentrations). At the surface, PN was the major product of uptake, accounting for 61 to $89 \%$ of the gross uptake. The relative importance, as well as the magnitude of the rate of DON release versus net uptake, increased with depth so that at $30 \mathrm{~m}, \mathrm{DON}$ release accounted for both day and night, with the single exception of the larger size fraction at $1 \mathrm{~m}$ at night (Fig. 4). Except for this one sample, DON release accounted for more than $67 \%$ of gross uptake from $\mathrm{NO}_{3}{ }^{-}$, often as much as $98 \%$. Most of the net uptake occurred in the larger size fraction but, except at $1 \mathrm{~m}$, it appeared that inclusion of the larger size fraction had no effect on the rate of DON release from $\mathrm{NO}_{3}{ }^{-}$, relative to its release by the small fraction alone.

\section{DISCUSSION}

Relatively few previous studies have reported directly upon the magnitude of DON release in marine systems, but both direct and indirect evidence has suggested that the DON flux is significant (Laws 1984, Ward et al. 1989, Bronk \& Glibert 1991, 1993a,b, Bronk et al. 1994, 1998, Slawyk \& Raimbault 1995, Pujo-Pay et al. 1997, Hu \& Smith 1998, Slawyk et al. 1998). The magnitude of DON release rates reported here varied from below detection to essentially $100 \%$ of gross production (DON release plus net uptake).

To interpret the present results, we began by identifying common patterns of DON release and net uptake and then deduced mechanisms that would be consistent with those patterns. The results are first discussed in light of conventional understanding of nitrogen assimilation and regeneration processes and ecosystem functioning. Subsets of the results are then considthe overall findings. A schematic of the processes inferred to be responsible for the patterns is shown in Fig. 5, and the components are discussed in the followered in a series of comparisons, in a larger synthesis of 


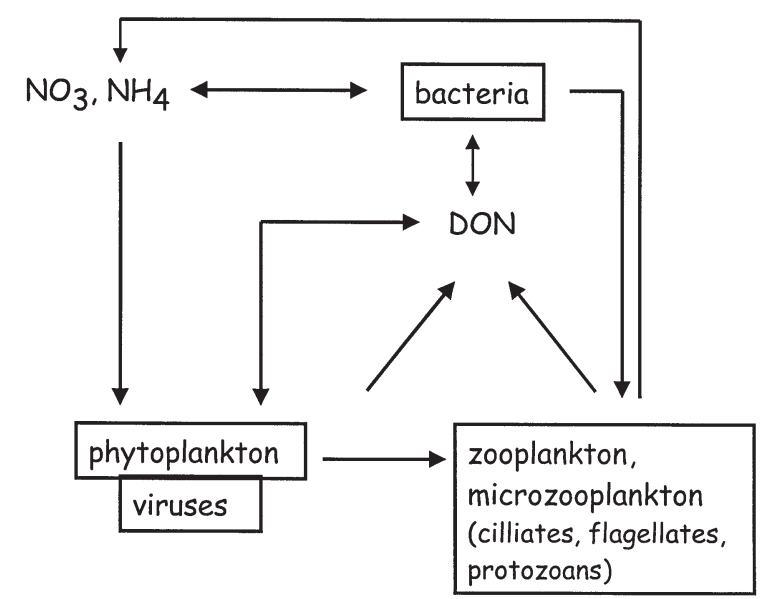

Fig. 5. Schematic of processes involved in DON production and potential interactions between size fractions

ing sections. The calculations used to compute DON release assume that the DON release detected in these experiments is derived from DIN that was taken up from the seawater during the incubation. DON release does not represent the mineralization of $\mathrm{PN}$ that was present at the beginning of the incubation. Rather, the release represents a rapid flux from the DIN pool, through the PN pool in a transient stage (mechanisms will be discussed below), and then into the DON pool. Breakdown of existing PN would not be detected in the DON pool by the ${ }^{15} \mathrm{~N}$ tracer methods used here. It would, however, contribute to $\mathrm{NH}_{4}{ }^{+}$regeneration detected by isotope dilution of the added ${ }^{15} \mathrm{NH}_{4}{ }^{+}$substrate.

\section{Functional interpretation of experimental results}

$$
\text { Preference for } \mathrm{NH}_{4}{ }^{+} \text {versus } \mathrm{NO}_{3}^{-}
$$

An apparent preference for uptake of $\mathrm{NH}_{4}{ }^{+}$over $\mathrm{NO}_{3}{ }^{-}$is commonly observed, even at low nutrient concentrations (Harrison et al. 1996) and was frequently observed in the experiments reported here. For example, the difference in net uptake (into PN) between $\mathrm{NH}_{4}{ }^{+}$and $\mathrm{NO}_{3}{ }^{-}$at all depths in March is consistent with the preference for $\mathrm{NH}_{4}{ }^{+}$by phytoplankton in the absence of high $\mathrm{NO}_{3}{ }^{-}$concentrations. Relatively high net uptake from $\mathrm{NO}_{3}{ }^{-}$was observed only at $19 \mathrm{~m}$ where $\mathrm{NO}_{3}{ }^{-}$concentrations were relatively higher. The preference for $\mathrm{NH}_{4}{ }^{+}$was also observed in the September $\mathrm{MB}$ experiments, but the disparity between $\mathrm{NH}_{4}^{+}$ and $\mathrm{NO}_{3}^{-}$uptake into $\mathrm{PN}$ was less pronounced in September. This trend is consistent with the results of single endpoint incubations throughout the surface layer from these cruises reported previously (Bronk \&
Ward 1999), in which the March samples showed an overwhelming reliance on $\mathrm{NH}_{4}{ }^{+}$, but a more equable use of $\mathrm{NH}_{4}{ }^{+}$and $\mathrm{NO}_{3}{ }^{-}$in September. The SCB results do not illustrate a clear preference for $\mathrm{NH}_{4}{ }^{+}$in terms of net uptake, partly because of missing data in the October experiments and the presence of high $\mathrm{NO}_{3}{ }^{-}$in the $43 \mathrm{~m}$ experiment in April.

\section{Implication of grazing in nitrogenous nutrient regeneration}

Ammonium regeneration is associated with grazing, based on the assumption that breakage of cells during ingestion and rapid incomplete digestion by grazers should release labile internal pools and excretory products. While microzooplankton (cilliate, flagellate and even protozoan) grazers may be of the same size as their prey, many zooplankton grazers prey on phytoplankton smaller than themselves and can sometimes be separated from their prey by size fractionation. In the experiments reported here, $\mathrm{NH}_{4}{ }^{+}$regeneration rates often were higher in the incubations that contained the larger size fraction than in those containing only the $<10 \mu \mathrm{m}$ fraction (3 of 3 experiment for March MB, 2 of 5 of the September MB experiments, 4 of 6 experiments for which the comparison is possible in the $\mathrm{SCB}$ ). The increase in $\mathrm{NH}_{4}{ }^{+}$regeneration in March associated with the large size fraction is consistent with the observation that the chl/PN ratio was greater in the small fraction, implying a disproportionate representation of phytoplankton in the small fraction and of heterotrophs in the large fraction. In September, chl:PN ratios (Table 2) were higher in the large fraction than in the small except in the daytime ${ }^{15} \mathrm{NH}_{4}{ }^{+}$ experiment, implying a more equitable distribution of phytoplankton and heterotrophs in both size fractions. (Most of the chl a was in the small fraction in the September experiments, but the chl:PN ratios indicate that an even greater proportion of the heterotrophsincluding potential grazers - were in the small fraction as well.)

Grazing is one process that may be responsible for part of the DON release, by analogy with $\mathrm{NH}_{4}{ }^{+}$regeneration. In Fig. 5, the arrow leading from zooplankton to $\mathrm{NH}_{4}{ }^{+}$represents both excretion and release during grazing $\left(\mathrm{NO}_{3}{ }^{-}\right.$is not produced in this manner but is listed next to $\mathrm{NH}_{4}{ }^{+}$as one of the inorganic substrates taken up by phytoplankton). Grazing might break open cells and release low molecular weight N-rich DON components that have not yet been assimilated into macromolecular or structural components (Bronk \& Glibert 1993a). Labile DON might also be released by excretion during grazing (Jumars et al. 1989). If grazing were responsible for both $\mathrm{NH}_{4}{ }^{+}$regeneration and DON 
release, we would expect a correlation between the magnitudes of the 2 rates. Such a comparison is of course possible only for the ${ }^{15} \mathrm{NH}_{4}{ }^{+}$incubations (because we do not have $\mathrm{NH}_{4}{ }^{+}$regeneration measurements in the ${ }^{15} \mathrm{NO}_{3}{ }^{-}$bottles) and is shown in Fig. 6 . The correlation coefficient $\left(\mathrm{R}^{2}\right)$ of 0.804 (with $\mathrm{N}=29$; both DON release and $\mathrm{NH}_{4}{ }^{+}$regeneration data were obtained from 30 of 38 experiments but 1 outlier, shown, was omitted from the regression) is significant at the $p<0.00001$ level (Table 3). The regression coefficient (slope of the model II regression) implies that the rate of $\mathrm{N}$ release as DON is about half the rate of $\mathrm{NH}_{4}{ }^{+}$regeneration. The correlation suggests that on the order of $80 \%$ of the variability in the DON release rates can be accounted for by covariance with $\mathrm{NH}_{4}{ }^{+}$regeneration, which is consistent with both rates being at least partially controlled by the same process, i.e., grazing. If the 2 size fractions are treated separately, the slopes and regression coefficients are significant for both data sets, but the correlation is stronger for the larger fraction (Table 3). These correlations are compelling evidence that DON release results from trophic dynamic interactions such as grazing and excretion, rather than from an experimental artifact.

Glibert et al. (1992) used size fractionation experiments to investigate the dependence of $\mathrm{NH}_{4}{ }^{+}$regeneration on grazing. They reported that $\mathrm{NH}_{4}{ }^{+}$regeneration rates in small fractions sometimes greatly exceeded the rates when the larger fraction, presumably containing the grazers, was present. They concluded that the rate of regeneration is a nonlinear function of the grazer abundance or multiple trophic interactions. The same caveats apply to the inference of grazing in the DON release data reported here. If small protozoan, ciliate or flagellate grazers were included in the small fraction, then size fractionation

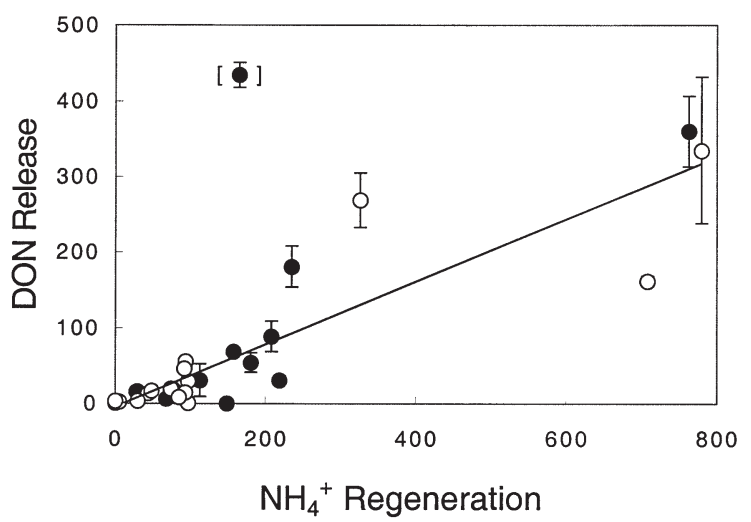

Fig. 6. Scatter plot of DON and PN production rates. Line represents regression for all experiments combined. Symbols: (O) $<10 \mu \mathrm{m}_{i}(\bullet)<210 \mu \mathrm{m}$. See Table 3 for model II regression coefficients would be inadequate to separate the trophic levels and some amount of grazing, and associated DON release and $\mathrm{NH}_{4}{ }^{+}$regeneration, can be expected to occur in the small fraction most of the time.

\section{Regional productivity variation}

The SCB, inside the zone of coastal upwelling, is a generally more oligotrophic, lower primary production area than is upwelling-dominated MB. Lower productivity rates and smaller cell sizes were thus expected for the SCB relative to MB. This generalization was substantiated by the depth profiles of primary production measured on these cruises (not shown, Bronk \& Ward 1999, unpubl. data) in which production on a volume basis in MB exceeded that in SCB by more than a factor of 10 for many samples in the euphotic zone. The size distribution of chl $a$ is also basically consistent with this generalization: most of the chl $a$ was in the large size fraction in the March experiments except in the surface samples, and in September MB, only 1 incubation (day ${ }^{15} \mathrm{NH}_{4}{ }^{+} 30 \mathrm{~m}$ ) was dominated by small phytoplankton. The dominance of small phytoplankton was noted in about 5 of the 12 SCB incubations from October (chl a data are not available for April SCB experiments). The $10 \mu \mathrm{m}$ cutoff we used may not be optimal for functional separation but it did allow us to detect distinct trends in phytoplankton size in the 2 environments.

\section{Depth distribution of rates}

These experiments were not designed to investigate the many factors, such as light intensity, nutrient and light history, ambient nutrient concentrations, etc., that are well known to influence the observed depth distribution of $\mathrm{NO}_{3}{ }^{-}$and $\mathrm{NH}_{4}{ }^{+}$assimilation. We can, however, address briefly the relations between DON release, DIN incorporation, and depth. For example, in April (SCB), higher uptake rates for $\mathrm{NO}_{3}{ }^{-}$would be expected at the deeper depth, where $\mathrm{NO}_{3}{ }^{-}$concentrations were relatively higher. Ammonium concentrations, by contrast, were low and nearly undetectable at both depths sampled for these experiments. Low $\mathrm{NO}_{3}{ }^{-}$ assimilation rates into $\mathrm{PN}$ are consistent with the observations of others and with the prevailing view that the energy requirement for $\mathrm{NO}_{3}{ }^{-}$assimilation by phytoplankton reduces the capability for $\mathrm{NO}_{3}{ }^{-}$uptake at night. However, the observation of large DON release rates in the deep April samples suggests that actual uptake of $\mathrm{NO}_{3}{ }^{-}$is not limited at night. Rather, its incorporation into particulate material is reduced, either because of grazing or of energy limitation for macromolecule synthesis, resulting in large DON 
Table 3. Correlation coefficients for model II regressions between DON release rates and $\mathrm{NH}_{4}$ regeneration rates in size fraction experiments (DON release $=\left[\mathrm{NH}_{4}\right.$ regeneration $\times \mathrm{m}]-$ intercept)

\begin{tabular}{|lcccccc|}
\hline & $\mathrm{N}$ & $\mathrm{R}^{2}$ & $\mathrm{~m}$ & Intercept & $\mathrm{p}$ \\
\hline All experiments & 29 & 0.804 & 0.489 & 44.1 & $<0.00001$ \\
$<210 \mu \mathrm{m}$ only & 14 & 0.875 & 0.533 & 40.1 & $<0.00002$ \\
$<10 \mu \mathrm{m}$ only & 15 & 0.757 & 0.457 & 47.0 & $<0.00001$ \\
\hline
\end{tabular}

fluxes rather than net uptake (see below for discussion of mechanisms of DON release). In the parallel ${ }^{15} \mathrm{NH}_{4}{ }^{+}$ incubations in April, net uptake and DON release rates were lower at $43 \mathrm{~m}$ than at $3.5 \mathrm{~m}$, while regeneration was relatively more important at depth. Clearly, the type of DIN substrate is also important in determining the fate of nitrogen as a function of depth.

\section{Synthesis and inferences}

Meaning of DON release from large versus small fraction; the importance of grazing

The major finding of this report is that DON release occurs over short time scales in simulated in situ incubations sampled from depths throughout the photic zone, in coastal, upwelling, and oceanic environments, when either $\mathrm{NH}_{4}{ }^{+}$or $\mathrm{NO}_{3}{ }^{-}$is utilized as a substrate. The mechanism of DON release remains obscure, but it has been cogently argued that passive or active release by healthy phytoplankton in the absence of stress or grazing is unlikely (Sharp 1977) because of energetic and nutrient limitation considerations. Bronk (1999) found that in cultures of the marine cyanobacterium Synechococcus, the cells did not release substantial amounts of DON even under conditions of nitrogen starvation, although nitrogen starvation conditions are often associated with high rates of DOC release. It seems most likely, therefore, that interactions among members of the community, probably grazing and predation or parasitism, as well as potentially nutrient (see above) and light stress (Lomas \& Glibert 1999) or limitation, are important in controlling DON release. Some of these potential interactions are visualized in Fig. 5 as depending upon the structure of the community as well as the ambient nutrient conditions. It is recognized that both heterotrophic bacteria and phytoplankton are involved in assimilation of DON but these fluxes would not be distinguished by the experimental design used here.

As described above, these experiments were aimed primarily at discerning the effect of grazing on DON release, by analogy with $\mathrm{NH}_{4}^{+}$regeneration. It was expected that the presence of grazers would enhance DON release. There are many possible outcomes resulting from the inclusion of the large fraction compared with the small fraction alone: increase or decrease in DON release or net uptake, no change in either or any combination of these outcomes. The change of greatest interest is an increase in DON release, which implies that some interaction between trophic levels is important in causing DON release. In 12 of the 38 experiments, DON release was greater in the $<210 \mu \mathrm{m}$ fraction than in the small fraction alone. The simplest explanation would be that the primary producers are predominantly in the small fraction and the grazers are all in the large fraction.

Recognizing that size fractionation rarely provides an unequivocal separation of trophic groups, it is nevertheless possible to use chl $a$ and PN data to infer the size distribution of the 2 trophic classes: phytoplankton and grazers that feed on phytoplankton or other zooplankton (grazers include protozoans that may feed primarily on bacteria). Chl $a$ is used as a proxy for the presence of live primary producers and PN as a proxy for total biomass. Of course chl $a$ is inadequate to represent the diversity of primary producers (which have variable ratios of chl $a$ and other pigments to $\mathrm{PN}$ ) and PN may be associated with non-living material, but these widely measured parameters may still provide insight in the absence of detailed microscopic observation of community composition.

In some of the experiments in which DON release increased upon addition of the large fraction, chl $a$ and PN distributions indicate that large grazers preyed on small phytoplankton. That is, the chl:PN ratios indicate that most of the chl a was in the small fracation and disproportionately more PN (e.g., grazers without chlorophyll) were in the large fraction (e.g., September day $\mathrm{NH}_{4}{ }^{+} 30 \mathrm{~m}$, October coastal $\mathrm{NH}_{4}{ }^{+} 3.5 \%$ light, October oceanic $\mathrm{NO}_{3}^{-} 1 \%$ light). In other experiments (e.g., experiments March day $\mathrm{NH}_{4}{ }^{+} 4 \mathrm{~m}$ and $19 \mathrm{~m}$, September day $\mathrm{NO}_{3}^{-} 0 \mathrm{~m}$ ), both $\mathrm{chl}$ a and $\mathrm{PN}$ were predominantly in the large fraction, so grazing and DON release increased when that fraction was added, with little interaction from the small fraction.

It is likely that grazing is involved in DON release even in experiments in which DON release was unchanged by the addition of the large fraction (e.g., experiments March day $\mathrm{NH}_{4}{ }^{+} 16 \mathrm{~m}$, March day $\mathrm{NO}_{3}{ }^{-}$ 16 and $19 \mathrm{~m}$, September day $\mathrm{NO}_{3}^{-} 20 \mathrm{~m}$, September night $\mathrm{NO}_{3}{ }^{-} 30 \mathrm{~m}$ ). If both the grazers and the chl $a$ are mainly in the small fraction, then addition of the large fraction might have no effect, and trophic interactions within the small fraction alone would result in DON release. These cases are important to consider because they indicate that DON release occurs even in standard incubations. The strong correlation between 
$\mathrm{NH}_{4}{ }^{+}$regeneration and DON release implies that grazing has the potential to influence the fate of DIN in any incubated sample.

In some experiments, inclusion of the larger fraction may have reduced grazing pressure on phytoplankton in the small fraction if grazers in the large fraction prey on protozoans or small copepods, which preyed on the small phytoplankton. In this case, the effect of including the large fraction would be to reduce DON release (e.g., March day $\mathrm{NO}_{3}{ }^{-} 4 \mathrm{~m}$, October coastal $\mathrm{NO}_{3}{ }^{-} 1 \%$ light, October oceanic $\mathrm{NO}_{3}^{-} 3.5 \%$ light).

Significance of DON release from $\mathrm{NH}_{4}{ }^{+}$versus $\mathrm{NO}_{3}{ }^{-}$

Another factor that may influence the pattern of DON release rates arises from the potential for $\mathrm{NH}_{4}{ }^{+}$ and $\mathrm{NO}_{3}^{-}$to be taken up by different functional groups. Conventional wisdom suggests that larger phytoplankton are more likely to dominate $\mathrm{NO}_{3}{ }^{-}$ assimilation, and smaller picoplankton and heterotrophic bacteria are more likely to be involved in $\mathrm{NH}_{4}{ }^{+}$ assimilation. This may be simply a correlate of the idea that smaller primary producers are associated with the microbial loop and regenerated production while larger diatoms often dominate new production. The primary producers were generally smaller in the SCB than in MB (Table 2; see below), and DON production was detected in the $\mathrm{SCB}$ from both $\mathrm{NH}_{4}{ }^{+}$and $\mathrm{NO}_{3}{ }^{-}$. For example, in October, high DON release rates from $\mathrm{NH}_{4}{ }^{+}$at $3.5 \%$ light and $1 \%$ light, caused mainly by the small fraction, imply that if grazing is partly responsible for DON release, then most of the grazers in this system were small enough to be included in the $<10 \mu \mathrm{m}$ fraction. The October data differ from the April results in showing high DON release rates from both $\mathrm{NH}_{4}{ }^{+}$and $\mathrm{NO}_{3}{ }^{-}$. No significant $(\mathrm{p}>0.05$ ) correlations between net uptake or DON release rates and total chl $a$ or the fraction of chl $a$ in the $<10 \mu \mathrm{m}$ fraction were detected. There was also no apparent relation between total chl $a$ or the fraction of chl $a$ in the $<10 \mu \mathrm{m}$ fraction and the rates of net uptake or DON release from $\mathrm{NH}_{4}{ }^{+}$ or $\mathrm{NO}_{3}{ }^{-}$considered separately. Evidently, size alone, at least at the resolution of these experiments, is not sufficient to differentiate the relevant functional groups.

Both heterotrophic bacteria (secondary producers) and photosynthetic phytoplankton (primary producers) assimilate $\mathrm{NH}_{4}{ }^{+}$, but the phytoplankton are assumed to dominate $\mathrm{NO}_{3}{ }^{-}$assimilation (Kirchman \& Wheeler 1998). Therefore, one might expect to see differences in the rates of net uptake and DON release from the 2 substrates, depending on the relative importance of small versus large phytoplankton. If most of the primary producers were in the large fraction, then most
$\mathrm{NO}_{3}{ }^{-}$uptake would be associated with that fraction, while $\mathrm{NH}_{4}{ }^{+}$uptake would be preferentially associated with the smaller fraction. The methods used here undersampled $\mathrm{PN}$ in the bacterial fraction because GF/F filters were used to capture the PN (Altabet 1990). We have no information on DON loss during grazing on bacteria but would expect predation on bacteria to result in DON release because of the relative enrichment of bacterial biomass in $\mathrm{N}$ compared with most grazer biomass. Excretion in this case is usually thought to be in the form of $\mathrm{NH}_{4}{ }^{+}$(Caron 1991) but some release of small DON compounds from fecal matter production (Jumars et al. 1989) might also be expected. In this situation, some DON release would result from $\mathrm{NH}_{4}{ }^{+}$but there would be little DON release or net uptake from $\mathrm{NO}_{3}{ }^{-}$in the small fraction. Inclusion of the large fraction would increase net uptake and DON release from both $\mathrm{NH}_{4}{ }^{+}$and $\mathrm{NO}_{3}{ }^{-}$. The March $19 \mathrm{~m}$ experiment (Fig. 1) might be an example of this scenario: DON release from $\mathrm{NO}_{3}{ }^{-}$was less than from $\mathrm{NH}_{4}{ }^{+}$in the small fraction, net uptake from $\mathrm{NO}_{3}{ }^{-}$ increased much more than net uptake from $\mathrm{NH}_{4}{ }^{+}$when the larger fraction was present, and DON release from both $\mathrm{NH}_{4}{ }^{+}$and $\mathrm{NO}_{3}{ }^{-}$increased in the presence of the larger fraction. This is the only clear case of this kind, however, implying that in most of the samples, primary producers or bacteria that could assimilate $\mathrm{NO}_{3}{ }^{-}$were present in both the small and large fractions; the results do not include a single case in which $\mathrm{NO}_{3}^{-}$ uptake did not result in some release of DON.

A similar situation may have prevailed in the September MB night experiments. At all 3 depths, most of the phytoplankton were in the larger fraction at each depth. Consider the September $1 \mathrm{~m}$ night experiments (Fig. 4). Very little $\mathrm{NO}_{3}{ }^{-}$was assimilated into $\mathrm{PN}$ in the small fraction (about $10 \%$ of the amount of net uptake in the large fraction) but $\mathrm{NH}_{4}{ }^{+}$assimilation by the small fraction was $41 \%$ of the rate of assimilation by the larger fraction. Inclusion of the large fraction caused a decrease in DON release from both $\mathrm{NH}_{4}{ }^{+}$ and $\mathrm{NO}_{3}{ }^{-}$. This observation is consistent with the scenario in which large grazers prey on small grazers and thus remove grazing pressure on the phytoplankton.

DON release from uptake of $\mathrm{NO}_{3}{ }^{-}$is perhaps more intriguing than from $\mathrm{NH}_{4}{ }^{+}$because it is predominantly (although not exclusively) associated with $\mathrm{N}$ assimilation by phytoplankton, rather than bacteria, and because the energy requirement for $\mathrm{NO}_{3}{ }^{-}$assimilation and reduction is larger than for $\mathrm{NH}_{4}{ }^{+}$assimilation. It seems, therefore, counterintuitive that massive amounts of DON would be lost soon after $\mathrm{NO}_{3}{ }^{-}$uptake. However, if we consider that DON release probably results from grazing or stress, rather than passively accompanying assimilation, then greater loss of DON 
from $\mathrm{NO}_{3}{ }^{-}$than from $\mathrm{NH}_{4}$ might be expected. The requirement for more energy, and perhaps more time, to fully incorporate $\mathrm{N}$ from $\mathrm{NO}_{3}{ }^{-}$into macromolecules might result in larger transient pools of low molecular weight DON during $\mathrm{NO}_{3}{ }^{-}$versus $\mathrm{NH}_{4}{ }^{+}$uptake and assimilation. These pools would constitute the material lost by cell breakage during grazing. They might also contribute to DON released by excretion by grazers during grazing; they would be more labile than the macromolecules of particulate phytoplankton biomass. While their lability would enhance their direct assimilation by grazers, it would also increase their loss during rapid processing of high quality food (Jumars et al. 1989).

\section{Other causes of DON release}

It has been suggested that DON release, observed in incubation experiments, results from sample handling perturbations and is not a natural phenomenon. The potential for filtration artifacts was recognized and therefore all samples were filtered in reduced light and at low pressure with special care not to allow the filters to run dry. Nevertheless, a contribution from mechanical stress to the organisms cannot be ruled out. In favor of the predominantly 'natural' nature of these results, however, we suggest that the patterns observed, and the consistency of the relation between $\mathrm{NH}_{4}{ }^{+}$regeneration and DON release, would not be discernable if simple mechanical stress were responsible for random DON loss from cells. Mechanical stress would be expected to result in essentially random distributions of DON release-higher when the cells were accidentally but unknowingly stressed and lower when by chance they were not disturbed.

Susceptibility to mechanical stress probably varies with cell type, which cannot be assessed without direct information on the taxonomic composition of the primary producers in the samples. A reasonable hypothesis might be, however, that larger cells are more susceptible than smaller ones to mechanical stress leading to cell breakage and leaking. Some of the small photosynthetic cells are prokaryotes and thus have tough cell walls and are difficult to break open, supporting the idea that at least some of the primary producers in the small fraction would be less susceptible to mechanical stress-induced DON release than cells in the larger fraction. Therefore, inclusion of the large fraction in the incubation would be expected to increase DON release relative to the small fraction alone. However, 1 of the 2 most commonly observed results was that inclusion of the larger fraction in the incubation resulted in an increase in net uptake rates but a decrease in DON release rates. This pattern is attributed to a predominance of grazers in the larger fraction and is inconsistent with mechanical stress as the main cause of DON release.

During the April and October SCB cruises and the September $\mathrm{MB}$ cruise, rates of $\mathrm{DON}$ release, resulting from $\mathrm{NO}_{3}^{-}$uptake, often greatly exceeded net $\mathrm{NO}_{3}{ }^{-}$ uptake rates, and this trend increased with depth. This observation is consistent with earlier work of Ward et al. (1989) in the SCB, which found that during ${ }^{15} \mathrm{~N}$ experiments with $\mathrm{NO}_{3}{ }^{-}$, up to $93 \%$ of the total added ${ }^{15} \mathrm{~N}$ label could not be recovered in the $\mathrm{NO}_{3}{ }^{-}, \mathrm{NO}_{2}{ }^{-}$, or $\mathrm{PN}$ pools at the end of an incubation (shorter incubations resulted in higher recoveries, part of the reason for the experimental design used here). The Ward et al. (1989) results are consistent with a large fraction of the missing ${ }^{15} \mathrm{~N}$ being sequestered in DON that was not analyzed at the time. In the experimental data presented here, the amount of ${ }^{15} \mathrm{~N}$ label added as $\mathrm{NO}_{3}{ }^{-}$that was recovered in the DON pool averaged $5.5 \pm 3.5$ and $17.2 \pm 21.6 \%$ for all size fractionation experiments in $\mathrm{MB}$ and the SCB, respectively. Though we did not observe the extremely high losses of ${ }^{15} \mathrm{~N}$ seen by Ward et al. (1989), losses of ${ }^{15} \mathrm{NO}_{3}{ }^{-}$to the DON pool did reach as high as $59 \%$ in the SCB in October. Most importantly, these data show that a total mass balance for added tracer would not be obtained in a typical surface layer ${ }^{15} \mathrm{~N}$ incubation experiment in which the label in DON was not quantified. One possible explanation for these observations relates to the $\mathrm{NO}_{3}{ }^{-}$reductase photoprotective futile cycle proposed by Lomas \& Glibert (1999), who found that diatoms release reduced nitrogen compounds, including DON, when they are exposed to high light when growing in $\mathrm{NO}_{3}{ }^{-}$concentrations in excess of their nutritional requirements at low light in cold waters. The mechanism of the release is the intracellular reduction of $\mathrm{NO}_{3}{ }^{-}$via $\mathrm{NO}_{3}{ }^{-}$reductase as a means of protecting the photosystems from high photon flux. The exposure to high light in our samples could have occurred when the sample was dispensed from the Go-Flo to the incubation bottles. While this mechanism may play a part in some of the results presented here, it seems unlikely that it could suffice to explain the patterns reported here for a range of depths and sizes of phytoplankton. (Diatoms were present mainly in the larger size fraction. Therefore, the fact that DON release in the large fraction was not consistently more than in the small fraction argues against this being a general explanation.) The photoprotective futile cycle does, however, describe a mechanism that may affect samples differentially, and may be a factor in DON release in nature, especially during deep mixing events.

From this consideration of potential causes and mechanisms of DON release, we conclude that grazing, both through the mechanism of cell breakage and leakage, and through excretion accompanying growth 
of grazers, is the most likely cause of DON release in these experiments. DON release should almost always accompany net uptake, and it accompanies primary production measured by other means such as ${ }^{14} \mathrm{CO}_{2}$ incorporation because grazers cannot be completely separated from their prey by size fractionation or dilution in the commonly used incubation experimental strategies.

\section{CONCLUSIONS}

These experiments showed clearly that DON production can be an important nitrogen flux in planktonic communities under many different conditions of nutrient availability, light, and community structure. Several different scenarios of trophic and community structure are compatible with the several patterns of results we obtained, and are consistent with the suggestion that grazing is responsible for a significant fraction of DON release. We infer from these results and simple measurements of community structure on the basis of size fractionation that the size and species composition of the community are important variables in determining the rate of DON release. Because of the lack of complete correlation between trophic structure and organism size (Glibert et al. 1992), it is not possible to interpret these results completely on the basis of the chl $a$ and PN information collected with these experiments. In order to test some of the hypotheses described above as explanations for the observed patterns of PN and DON production, and of the effect of different size fractions in increasing or decreasing rates, it may be necessary to focus more specifically on the actual species composition of the community. Nevertheless, DON release during incubation experiments is ubiquitous, and this implies that the mechanism responsible for it is ubiquitous in incubation experiments in general. This suggests that even standard primary production measurements may underestimate the phytoplankton growth if grazing occurs in the incubation bottle.

Acknowledgements. Ken Bruland loaned the deck incubators for 3 of the cruises and Ed Renger loaned them for the October 1992 cruise. Mary Hogan, Don Bard, Elizabeth Hale, Justin Whittall, and Margaret Geissler all helped on the cruises and with the massive numbers of nutrient and isotopic analyses required for this project. CHN samples from the first 3 cruises were analyzed by Sandy Moore, OSU. This research was supported by NSF grants to B.B.W.

\section{LITERATURE CITED}

Altabet MA (1990) Organic C, N, and stable isotopic composition of particulate matter collected on glass-fiber and aluminum oxide filters. Limnol Oceanogr 35:902-909
Armstrong FAJ, Tibbits S (1968) Photochemical combustion of organic matter in seawater, for nitrogen, phosphorus, and carbon determination. J Mar Biol Assoc UK 48: 143-152

Bevington PR (1969) Data reduction and error analysis for the physical sciences. McGraw-Hill, New York

Bronk DA (1999) Rates of $\mathrm{NH}_{4}{ }^{+}$uptake, intracellular transformation, and dissolved organic nitrogen release in two clones of marine Synechococcus spp. J Plankton Res 21: 1337-1353

Bronk DA, Glibert PM (1991) A ${ }^{15} \mathrm{~N}$ tracer method for the measurement of dissolved organic nitrogen release by phytoplankton. Mar Ecol Prog Ser 77:171-182

Bronk DA, Glibert PM (1993a) Contrasting patterns of dissolved organic nitrogen release by two size fractions of estuarine plankton during a period of rapid $\mathrm{NH}_{4}{ }^{+}$consumption and $\mathrm{NO}_{2}^{-}$production. Mar Ecol Prog Ser 96: 291-299

Bronk DA, Glibert PM (1993b) Application of a ${ }^{15} \mathrm{~N}$ tracer method to the study of dissolved organic nitrogen uptake during spring and summer in Chesapeake Bay. Mar Biol 115:501-508

Bronk DA, Glibert PM (1994) The fate of the missing ${ }^{15} \mathrm{~N}$ differs among marine systems. Limnol Oceanogr 39:189-194

Bronk DA, Ward BB (1999) Gross and net nitrogen uptake and DON release in the euphotic zone of Monterey Bay, California. Limnol Oceanogr 44:573-585

Bronk DA, Glibert PM, Ward BB (1994) Nitrogen uptake, dissolved organic nitrogen release, and new production. Science 265:1843-1846

Bronk DA, Glibert PM, Malone TC, Banahan S, Sahlsten E (1998) Inorganic and organic nitrogen cycling in Chesapeake Bay: autotrophic versus heterotrophic processes and relationships to carbon flux. Aquat Microb Ecol 15: 177-189

Bronk DA, Lomas MW, Glibert PM, Schukert KJ, Sanderson MP (2000) Total dissolved nitrogen analysis: comparisons between the persulfate, UV and high temperature oxidation methods. Mar Chem 69:163-178

Caron DA (1991) Evolving role of protozoa in aquatic nutrient cycles. In: Reid PC et al. (eds) NATO ASI series, Vol G 25. Springer Verlag, Berlin, p 387-415

Dickson ML, Wheeler PA (1995) Ammonium uptake and regeneration rates in a coastal upwelling regime. Mar Ecol Prog Ser 121:239-248

Dugdale RC, Goering JJ (1967) Uptake of new and regenerated forms of nitrogen in primary productivity. Limnol Oceanogr 12:196-206

Eppley RW, Peterson BJ (1979) Particulate organic matter flux and planktonic new production in the deep ocean. Nature 282:677-680

Fiedler R, Proksch G (1975) The determination of ${ }^{15} \mathrm{~N}$ by emission and mass spectrometry in biochemical analysis: a review. Anal Chim Acta 78:1-62

Glibert PM, Lipschultz F, McCarthy JJ, Altabet MA (1982) Isotope dilution models of uptake and remineralization of ammonium by marine plankton. Limnol Oceanogr 27 : $639-650$

Glibert PM, Garside C, Fuhrman JA, Roman MR (1991) Timedependent coupling of inorganic and organic nitrogen uptake and regeneration in the plume of the Chesapeake Bay estuary and its regulation by large heterotrophs. Limnol Oceanogr 36:895-909

Glibert PM, Miller CA, Garside CC, Roman RM, McManus GB (1992) $\mathrm{NH}_{4}{ }^{+}$regeneration and grazing - interdependent processes in size-fractionated $\left(\mathrm{NH}_{4}{ }^{+}\right)-\mathrm{N}-15$ experiments. Mar Ecol Prog Ser 82:65-74 
Grasshoff K, Ehrhardt M, Kremling K (1983) Methods of seawater analysis. Verlag Chemie, Weinheim

Harrison WG, Harris LR, Irwin BD (1996) The kinetics of nitrogen utilization in the oceanic mixed layer: Nitrate and ammonium interactions at nanomolar concentrations. Limnol Oceanogr 41:16-32

Hu SH, Smith WO (1998) The effects of irradiance on nitrate uptake and dissolved organic nitrogen release by phytoplankton in the Ross Sea. Cont Shelf Res 18:971-990

Jones MN (1984) Nitrate reduction by shaking with cadmium. Water Res 18:643-646

Jumars PA, Penry DL, Baross JA, Perry MJ, Frost BW (1989) Closing the microbial loop: dissolved carbon pathway to heterotrophic bacteria from incomplete ingestion, digestion and absorption in animals. Deep-Sea Res 36:483-495

Kirchman DL, Wheeler PA (1998) Uptake of ammonium and nitrate by heterotrophic bacteria and phytoplankton in the sub-Arctic Pacific. Deep-Sea Res 45:347-365

Laws E (1984) Isotope dilution models and the mystery of the vanishing N-15. Limnol Oceanogr 29:379-386

Lomas MW, Glibert PM (1999) Temperature regulation of nitrate uptake: a novel hypothesis about nitrate uptake and reduction in cool-water diatoms. Limnol Oceanogr 44: $556-572$

Olson RJ (1981) ${ }^{15} \mathrm{~N}$ tracer studies of the primary nitrite maximum. J Mar Res 39:203-225

Parsons TR, Maita Y, Lalli C (1984) A manual of chemical and biological methods for seawater analysis. Pergamon Press, Oxford

Editorial responsibility: Osmund Holm-Hansen (Contributing Editor), La Jolla, California, USA
Pujo-Pay M, Conan P, Raimbault P (1997) Excretion of dissolved organic nitrogen my phytoplankton assessed by wet oxidation and N-15 tracer procedures. Mar Ecol Prog Ser 153:99-111

Raimbault P, Slawyk G, Boudjellal B, Coatanoan C, Conan P, Coste B, Garcia N, Moutin T, Pujo-Pay M (1999) Carbon and nitrogen uptake and export in the equatorial Pacific at 150 degrees W: evidence of an efficient regenerated production cycle. J Geophys Res (C Oceans) 104:3341-3356

Sharp JH (1977) Excretion of organic matter by marine phytoplankton: do healthy cells do it? Limnol Oceanogr 22: 381-399

Slawyk G, Raimbault P (1995) Simple procedure for simultaneous recovery of dissolved inorganic and organic nitrogen in ${ }^{15} \mathrm{~N}$-tracer experiments and improving the isotopic mass balance. Mar Ecol Prog Ser 124:289-299

Slawyk G, Raimbault P, Garcia N (1998) Measuring gross uptake of ${ }^{15} \mathrm{~N}$-labeled nitrogen by marine phytoplankton without particulate matter collection: evidence for low ${ }^{15} \mathrm{~N}$ losses to the dissolved organic nitrogen pool. Limnol Oceanogr 43:1734-1739

Strickland JDH, Parsons TR (1972) A practical handbook of seawater analysis, 2nd edn. Bull Fish Res Board Can 167

Ward BB, Talbot MC, Perry MJ (1984) Contributions of phytoplankton and nitrifying bacteria to ammonium and nitrite dynamics in coastal water. Cont Shelf Res 3:383-398

Ward BB, Kilpatrick KA, Renger EH, Eppley RW (1989) Biological nitrogen cycling in the nitracline. Limnol Oceanogr $34: 493-513$

Submitted: July 24, 2000; Accepted: February 1, 2001 Proofs received from author(s): August 22, 2001 